\title{
Cluster policy in conditions of innovative development of the region
}

\author{
Elena Ushakova ${ }^{1}$,Elena Voronina $^{1}$, Olga $\mathrm{Kim}^{1}$, and Elena Fugalevich ${ }^{1, *}$ \\ ${ }^{1}$ Saint Petersburg University of Management Technologies and Economics, Institute of Management \\ Economics and Information Technology, 190103, Saint Petersburg, Russia
}

\begin{abstract}
The development of regional clusters in the Russian Federation is one of the priority conditions for increasing the competitiveness and innovativeness of the domestic economy. The article deals with the most urgent issues of formation and development of clusters in the Russian Federation. The innovative cluster policy of the Leningrad Region is considered as an example. Priority directions for the development and implementation of the regional cluster policy in the conditions of innovative development of the territories are outlined.
\end{abstract}

\section{Introduction}

The development of territorial clusters in the regions of the Russian Federation is one of the most important conditions for increasing the competitiveness of the domestic economy and providing an innovative way for its development.

Generally, clusters are considered to be an object of industrial policy oriented at increasing the competitiveness of the state, region or industry. However, in practice the power of the cluster is formed at the microlevel, that is, at the level of individual enterprises that are able to produce goods and services in demand, which includes introducing new technologies in production and service. Thus, the efficiency of the business sector and, consequently, of territorial clusters, depends directly on the performance of specific enterprises, since more successful and productive companies attract more competent and qualified specialists, information they have is more complete and accurate, their management and control system is better, and their positions in the business environment are stronger. It should be noted that thus far, with such a high level of handling the concept of "cluster policy", its precise definition has not been proposed. This term is usually understood as a set of tools necessary for the formation of network territorial associations (clusters).

It is known that an effective innovation infrastructure that ensures the transfer of research results to the market of products and services is one of the most significant conditions for the innovative development of the country in general and the region in particular. In this context, innovative territorial clusters become the so-called "innovation springboard" towards the economy of the future.

What is a cluster policy in modern conditions in Russia? We define it as follows. Cluster policy is a system of government measures to support clusters that ensure the competitiveness

\footnotetext{
* Corresponding author: fugalevich_elena@mail.ru
} 
of regions and economic entities making up the cluster and the introduction of innovative technologies.

Today, one of the priority conditions for modernizing the Russian economy and implementing the competitive opportunities of the regions is the creation of a branching network of clusters. In the Russian Federation, the elements of cluster policy are defined in the Concept of Long-Term Social and Economic Development up to 2020. The Concept outlines a network of territorial clusters that implement the competitive potential of the territories to be created and a number of innovative high-tech clusters in the European and Asian parts of Russia to be formed. The innovative socio-economic development of the Russian Federation includes creation of two types of clusters, namely, innovative high-tech clusters (in the case of urbanized regions) and territorial production clusters. The second type of clusters is focused on the diversification of industry using high science-intensive technologies [5].

The main goal of implementing the cluster policy is to ensure high rates of economic growth and diversification of the economy by increasing the competitiveness of entities that form clusters, i.e. enterprises, suppliers of equipment, components, specialized production and aftersale services, research and educational organizations.

The development of territorial clusters in the regions of the Russian Federation in the conditions of an innovative economy is one of the most important requirements for increasing competitiveness and ensuring innovative development of the domestic economy.

Clusters are generally accepted to be an object of industrial policy. They are primarily focused on growth of competitiveness of the state, region or any separate branch. However, it is often forgotten that the true power of the cluster is formed at the microlevel, that is, at the level of individual economic entities that can produce competitive goods and services, which includes introducing new technologies into the production process and services. Based on the above, the efficiency of the business sector and, as a consequence, territorial clusters is directly dependent on the efficiency of the work of specific enterprises. This is due to the fact that more successful and efficient production companies attract more high-quality specialists having more complete and reliable information and have a better management and control system and more sound competitive positions in the business community.

This having been said, the main element of cluster policy in such conditions is the competitiveness of a particular cluster. In other words, stronger position of the cluster as a whole is achieved by increasing competition between enterprises within the cluster itself. Competition within the cluster contributes to the search and development of innovative management solutions and innovative ways of organizing production and management.

Based on the above, it can be argued that cluster policy combines the interests of regional policy, sectoral policy and innovation policy.

The implementation of cluster policy allows the greatest possible minimization of the administrative, economic and other barriers that impede interaction between economic entities being members of the cluster. In these circumstances, the authorities should be given a leading role in the development and implementation of cluster policy. This relates in the first place to the creation of the clusters infrastructure, ensuring information transparency, publicity and accessibility, rendering assistance in attracting various kinds of resources, etc. However, an important fact is that clusters have a different production orientation, which should be taken into account in order to avoid serious errors. Therefore, approaches to the implementation of cluster policy should differ depending on the specialization of the cluster.

\section{Methods of research}

Today, there are a number of strategies and tactics for implementing cluster policy. Particular attention is paid to the strategies and tactics that allow achieving maximum 
efficiency at minimum costs. In this regard, the most significant problem is the search for the most optimal way of organizing an up-to-date cluster policy. However, one should take into account that a particular policy that has been successful and effective for one cluster can be disastrous for another cluster. In order to prevent such a situation, regional authorities have to be completely aware of the characteristics of the territory under its jurisdiction, its uniqueness and potential.

Another important problem is misconception. Sometimes the authorities try to attract potential investors to their region by using the term "cluster". Here, this term is no more than a fashionable brand. In practice, it is quite often that in some regions large industrial enterprises for some political (or other) reasons are declared clusters, but in fact they are not.

A third problem in the implementation of cluster policy is the existence of differences in the interests and priorities between enterprises in the cluster. Importantly, there is a need to carry out measures to avoid conflicts that often arise between the participants of the cluster.

Today, the document entitled "The Strategy of Innovative Development of the Russian Federation up to 2020" puts emphasis on the need to support cluster initiatives. According to this document, it is assumed that the formation and development of innovative clusters will promote the energizing of innovative activity. At the first stage (2011-2013) a number of pilot projects were conducted to develop and adapt mechanisms for supporting cluster initiatives. In the future, the development of clusters will be stimulated through a mechanism for co-financing from the federal budget of regional programs to promote small businesses and additional support for the regions that are actively investing in the creation of their regional innovation system. Thus, for Russia, activation and development of clusters is a new approach to the formation of a modern innovative economy.

The creation of a cluster requires for the more energetic scientific activities of existing in the region specialized universities and research institutes or the creation of new ones, as well as the formation of an innovative infrastructure and the increase in the number of local private enterprises that provide science-intensive services.

Let us consider the role of the state in this process. Its place and role in the process of activation and development of clusters lies, first of all, in the fact that it is this institution that acts as one of three equal parties, each of them performing its specific functions. In Englishlanguage sources this approach is called "The Triple Helix Concept". In its essence, this approach implies that innovation development is the most extensive when there is a cooperation of three institutions: the state, business and the scientific community. However, experience shows that the relationship in the context of the creation or use of innovation is very often a "double helix". This is expressed in the following form: state - science, business - science, state - business. At the same time, processes of the modern society such as intensification and complication of innovative processes lead to the fact that bilateral relations gradually lose their effectiveness.

In Russia, due to the current economic and political conditions, there is a steadily functioning hierarchical system which includes bilateral relations. In these conditions, science and business are separately oriented on the state aid. However, they do not interact with each other.

Let us consider the Leningrad Oblast as an example. It is one of Russia's regions in which the development of the cluster system as the basis for the formation of an innovation-type economy is most effective.

Today, creation and development of industrial and innovative clusters in the region is one of the main mechanisms of economic growth aimed at implementing the competitive advantages of the Leningrad Oblast, the development of industry, the stimulation of innovative activity of enterprises and the increase in the level of cooperation among economic entities of the region. 
In this territory, the potential for the formation of clusters is rooted in the most competitive sectors of the specialization of the region's production, which are machine building, chemical and pharmaceutical industry, automotive industry, as well as in life support and human well-being, i.e. in a tourist-recreational cluster and a cluster of medical technologies.

The Government of the Leningrad Oblast sees the basis uniting the processes of formation and development of clusters in the promotion of innovations and in the development of promising technological platforms, as well as the scientific and technological bases of enterprises.

In the Leningrad Oblast, with its successful geographical location, a powerful industrial core, high scientific potential and a growing business infrastructure, several clusters are already being formed that are driving the innovative regional economy.

According to the plans, there should be at least ten of such clusters by 2025 . However, at present only some of them can really act as growth drivers. In crisis conditions, a budgetary resource, which is essential for creation of a proper cluster, should be dealt with as efficiently as possible, and investments should be made in something that will definitely bring returns, I.e., in the creation of the final product with a guaranteed sales market, either existing or quickly formed. Such clusters become key ones and ultimately promote the entire economy of the region [14].

The purpose of creating clusters on the territory of the Leningrad Oblast is to increase the level of cooperation among members of the cluster aimed at solving common problems and challenges that arise not only in one field of industry but also in related fields. This approach, when there is an with state authorities, allows concentration of the financial, labor, material, technical and innovation resources of the cluster participants on solving common problems and thereby acceleration of the growth of production and economic activities of enterprises and the economy of the region and increase of the competitiveness of domestic products.

\section{Results}

Clusters serve as a basis for creation of the favorable conditions for development and introduction of innovations and investment attraction, as well as for creation of an industrial, innovative and scientific and educational infrastructure.

A distinctive feature of industrial clusters is the possibility to reimburse up to $50 \%$ of the costs incurred to implement joint projects from the federal budget.

Within the innovation cluster, high-tech science-intensive projects are implemented with the interaction of science, education, production and the system of promotion and marketing of final products. The mutual complementation of these elements can provide accelerated economic growth through the development of high-tech innovative production.

Creation and development of industrial and innovative clusters can become growth driver not for only the regional economy but also for the Russian economy as a whole.

In order to concentrate the internal resources of industrial enterprises in strategically important sectors of the economy, as well as to speedily overcome the technology gap of domestic industry and introduce innovative technologies in production, a regional cluster policy is being implemented in the Leningrad Oblast.

To date, there are more than 11 cluster initiatives in the Leningrad Oblast, two clusters located in the Oblast being institutionalized and having a specialized organization: an innovative cluster of medical, pharmaceutical industry and radiation technologies (the NonProfit Partnership "Cluster of Medical, Pharmaceutical Industry and Radiation Technology"); industrial automobile cluster (Union "Autoprom North-West").

On February 15, 2018, within the framework of the Russian Investment Forum in Sochi, the Government of the Leningrad Oblast concluded an additional agreement with the 
Government of St. Petersburg and the specialized organization of the industrial cluster on the Agreement on the Establishment of an Industrial Cluster "Autoprom North-West" dated 01.06.2017 [15].

Priority cluster initiatives are as follows:

- shipbuilding cluster;

- cluster of construction materials;

- food industry cluster;

- petrochemical cluster;

- cluster of composite materials;

- forestry cluster.

Effective cluster policy should be based on a clear organization of permanent interaction between all levels of government, business and scientific and educational institutions to create joint efforts to improve the innovation of production processes and services, which will facilitate the improvement and increase of the effectiveness of the work of government, business structures and scientific community.

It should be noted that one of the priority guidelines of the cluster policy is to stimulate development and increase the innovative potential of small and medium-sized enterprises, which is relatively weak in the Russian economy in comparison with developed and developing countries. In this issue, it is necessary to develop and interlink regional programs aimed at the formation of innovative clusters with programs for the development and support of small and medium-sized businesses.

\section{Conclusions}

In our opinion, creation of regional development agencies can be a rather important measure of coordination of regional cluster initiatives. In terms of their internal content, these are some organizational structures, one of the purposes of which is to coordinate the implementation of long-term strategies and programs in general. Their activities should also be focused on the operational management of priority projects. For these structures, packages of regulatory documents defining their status and authority as well as a system of interaction with the main subjects of the regional economy should be developed.

Let us pay attention to one more condition which is in our opinion necessary for the development of regional clusters. This is the existence of a modern effective system aimed at attracting, training and retraining qualified personnel. Based on the essence of this system, the priority task of public authorities of the federal subjects of the Russian Federation should be to improve the quality of so-called "local" human resources, as well as create conditions for attracting qualified personnel from other regions and countries, which will further strengthen the competitive potential of regional clusters. Long-term maintenance of cluster competitiveness is possible only through a permanent innovation process, which, first of all, must be based on qualified personnel. In these conditions, effective support is needed for local scientific schools and local specialists who are able to preserve and increase unique knowledge about the properties of cluster resources.

The solution of such a personnel task is possible through the application of mechanisms that exist in employment policy, educational policy, small business policy and immigration policy of the respective region. These instruments should be applied in that very part which affects the development of regional clusters. Also, in our opinion, measures such as the actions on the part of the authorities aimed at creating a regional innovation system should be extremely important, which in the long run will help increase the intellectuality of cluster development.

To support the effective development of the cluster, state support is needed in matters of legislative, tax and general regulation. In this regard, it is important to adopt the law to more 
fully define the organizational and legal foundations for the operation of clusters. Carrying out a competent policy on these issues on the part of the state will help attract potential participants to join the cluster.

Thus, it can be concluded that the countries on whose territory the clusters are created become innovative leaders in world markets. At the moment, the creation of clusters is actively taking place in the territory of the Russian Federation. Implementing the cluster policy results in the growth of productivity and innovation activity of enterprises forming a cluster, as well as an increase in the development of small and medium-sized businesses, increased attraction of direct investment, sustainable innovation and socio-economic development of regions where clusters are located.

\section{References}

1. M.A. Volkova, Bulletin of the Siberian State Aerospace University 2, 438-442 (2009)

2. E.V. Voronina, I.A. Mavrina, E.V. Fugalevich, Evaluation of the effectiveness of the administrations of municipalities in the system of public administration of the regional economy. Monograph (Pushkin Leningrad State University, St. Petersburg, 2014)

3. E.V. Ioda, Yu.V. Ioda, I.A. Broslavsky, Socio-economic phenomena and processes 8, 39-44 (2016)

4. The Constitution of the Russian Federation (1993)

5. Concept of Long-Term Social and Economic Development of the Russian Federation up to 2020 (Government of the Russian Federation, 2008)

6. D. Carlton, Review of Economics and Statistics 3, 440-449 (1983)

7. P. Krugman, Journal of Regional Science 33:2, 129-144 (1993)

8. M. Porter, Economic Development Quarterly 14(1), 15-34 (2000)

9. D.P. Woodward, The Review of Regional Studies 42, 5-23 (2012)

10. G.A. Khmeleva, V.V. Vakhovsky, Bulletin of the Samara Municipal Management Institute 2, 90-97 (2012)

11. G.A. Khmeleva, E.V. Ioda, Bulletin of the Samara Municipal Management Institute 2, 7 (2011)

12. Official website of the government of the Russian Federation // http://government.ru

13. Official website of the Ministry of Economic Development of the Russian Federation //http://economy.gov.ru

14. Investment portal of the Leningrad Oblast // http://lenoblinvest.ru

15. Official site of the Committee for Economic Development and Investment Activity of the Leningrad Region //http://econ.lenobl.ru 